\title{
Relationships between growth, population dynamics, and environmental parameters in the solitary non-zooxanthellate scleractinian coral Caryophyllia inornata along a latitudinal gradient in the Mediterranean Sea
}

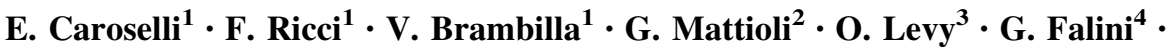 \\ Z. Dubinsky ${ }^{3} \cdot$ S. Goffredo ${ }^{1}$
}

Received: 17 April 2015/Accepted: 17 December 2015/Published online: 29 December 2015

(C) Springer-Verlag Berlin Heidelberg 2015

\begin{abstract}
The ecology of scleractinian corals may be understood through comparisons between population demographic data and environmental parameters. Growth (growth constant and maximum size) and demographic parameters (population structure stability, instantaneous mortality rate, average age of individuals, percentage of immature individuals, age at maximum biomass, and average age of biomass) of the solitary, non-zooxanthellate, and temperate coral Caryophyllia inornata were investigated at six sites along an $8^{\circ}$ latitudinal gradient of temperature and solar radiation (SR) on the western Italian coasts. Growth parameters were homogeneous among populations across the investigated latitudinal range. While demographic parameters were not correlated with depth temperature, populations were progressively less stable and showed a deficiency of young individuals with increasing SR, likely as a result of the lowered energetic resources due to reduced zooplankton availability. These results contrast with data from another Mediterranean non-zooxanthellate solitary coral, Leptopsammia pruvoti, investigated along
\end{abstract}

Communicated by Biology Editor Dr. Mark J. A. Vermeij

S. Goffredo

s.goffredo@unibo.it

1 Marine Science Group, Department of Biological, Geological and Environmental Sciences, University of Bologna, Via F. Selmi 3, 40126 Bologna, Italy

2 Operative Unit of Radiology and Diagnostics by Images, Hospital of Porretta Terme, Local Health Enterprise of Bologna, Via O. Zagnoni 5, 40046 Porretta Terme, Italy

3 The Mina and Everard Goodman Faculty of Life Sciences, Bar-Ilan University, 52900 Ramat Gan, Israel

4 Department of Chemistry "Giacomo Ciamician", University of Bologna, Via F. Selmi 2, 40126 Bologna, Italy the same gradient, which shows no correlation between population demography and temperature or SR.

Keywords Global warming - Demography - Temperate coral · Caryophylliid · Solar radiation · Temperature . Latitudinal gradient

\section{Introduction}

Many scleractinians are sensitive to environmental factors such as nutrients (Muscatine et al. 1989; Orejas et al. 2011), water flow (Purser et al. 2010), substrate slope and structure (Vertino et al. 2010), waves (Lasker 1990), pH (Goffredo et al. 2014; Fantazzini et al. 2015), light (Rodolfo-Metalpa et al. 2008), and temperature (Goffredo et al. 2008; Kružić et al. 2012). Latitude is the main factor influencing variation in solar radiation (SR) and sea surface temperature (SST; Kain 1989), which are widely used as monitoring parameters for ecological studies (Gerrodette 1979; Goffredo et al. 2008; Caroselli et al. 2012) and have notable implications for organism biology (CarricartGanivet 2004; Cantin et al. 2010; Caroselli et al. 2011; Kružić et al. 2012). The Mediterranean Sea extends for about $14^{\circ}$ of latitude, making it a good system model to study whether and how biological processes vary with SR and temperature along a latitudinal gradient (e.g., Goffredo et al. 2007). The latitudinal variation of SR and SST generally influences scleractinian demography and growth (Dodge et al. 1974; Hughes 1984; Goffredo et al. 2008; Cantin et al. 2010; Hamel et al. 2010), such as in the Mediterranean species Cladocora caespitosa that shows differential growth rates in response to temperature and nutrients (Kružić et al. 2012). Net calcification rates are frequently related to temperature in both temperate 
(Goffredo et al. 2009) and tropical corals (Lough and Barnes 2000; Rodolfo-Metalpa et al. 2006; Cooper et al. 2008; Cantin et al. 2010; Carricart-Ganivet et al. 2012). Coral reproductive cycles are often regulated by temperature and photoperiod (Chornesky and Peters 1987; Goffredo et al. 2006; Airi et al. 2014), and larval survivorship and development are influenced by many environmental parameters (Jokiel and Guinther 1978; Edmunds et al. 2001; Brooke and Young 2005; Graham et al. 2008). Physiological processes (e.g., calcification, photosynthesis, and respiration) of organisms, including corals, are strongly dependent on environmental conditions (Edmunds and Gates 2002; Reynaud et al. 2003; Krief et al. 2010).

Some aspects of the ecology of scleractinians may be understood by comparing population demographic data and environmental parameters (Goffredo et al. 2008; Caroselli et al. 2012). Some gorgonians, reef-building corals, and solitary scleractinians record annual growth bands in their skeleton (Dodge et al. 1974; Chadwick-Furman et al. 2000; Goffredo and Lasker 2008; Goffredo et al. 2010; Caroselli et al. 2012), which can be counted to determine their individual age. In some species where mechanisms decoupling growth from age (e.g., colony fragmentation, fusion, and partial mortality) are negligible (Hughes and Jackson 1985; Babcock 1991), growth and population dynamic models based on age can be applied to describe demographic characteristics (Grigg 1984; Chadwick-Furman et al. 2000; Goffredo et al. 2010; Caroselli et al. 2012). The Beverton-Holt age-based model is a population dynamic model that estimates demographic data based on the previous generation's data (Beverton and Holt 1956). Data on demographic parameters such as population turnover time can be used to design strategies for reef restoration and bioremediation of degraded coastal areas (Goffredo and Chadwick-Furman 2003; Goffredo and Lasker 2008).

This study focuses on Caryophyllia inornata (Duncan 1878), a non-zooxanthellate solitary scleractinian coral widely distributed in the Mediterranean Sea and in the eastern Atlantic Ocean, from the UK to Azores Islands, up to $100 \mathrm{~m}$ depth (Zibrowius 1980). The species colonizes shaded hard substrates like the vaults and walls of caves, crevices, and wrecks and, in some cases, can dominate coral cover (Zibrowius 1980; Caroselli et al. 2015b). Its abundance along western Italian coasts ranges from 100 to 1500 individuals $\mathrm{m}^{-2}$ (Caroselli et al. 2015b). Caryophyllia inornata is gonochoric, brooding and displays an unusual reproductive cycle characterized by continuous production of brooded and apparently agamic embryos by females, males, and sexually inactive individuals (Goffredo et al. 2012a; Marchini et al. 2015).

The aims of this study were (1) to determine whether the growth and demographic parameters of $C$. inornata from six populations were related to SR and temperature variation along a wide latitudinal gradient, and (2) to compare the responses of $C$. inornata and two solitary dendrophyllids, Balanophyllia europaea (zooxanthellate) and Leptopsammia pruvoti (non-zooxanthellate), previously investigated along the same latitudinal gradient with the same methods (Goffredo et al. 2008; Caroselli et al. 2012).

\section{Materials and methods}

\section{Sample collection}

Specimens of $C$. inornata (Fig. 1a) were collected between May 14, 2009, and April 14, 2011, from six sites along a latitudinal gradient in the Mediterranean Sea from $44^{\circ} 20^{\prime} \mathrm{N}$ to $36^{\circ} 45^{\prime} \mathrm{N}$ (Caroselli et al. 2015b; Fig. 2). The samples were collected at depths ranging from 11 to $16 \mathrm{~m}$, where a high population density of $C$. inornata has been reported (Caroselli et al. 2015b). Samples were collected from crevices (see Table 1 for the number of samples collected at each site), excluding the Elba site where they were collected under the wings of a sunken plane wreck. At each site, all samples were collected along a transect ranging between 4 and 8 square patches of $0.01 \mathrm{~m}^{2}$ each (number of patches: Genova, GN, $n=6$; Calafuria, $\mathrm{CL}, n=8$; Elba, LB, $n=4$; Palinuro, PL, $n=6$; Scilla, SC, $n=6$; Pantelleria, PN, $n=7$; Table 1).

\section{Sample analysis}

Specimens were dried at $50{ }^{\circ} \mathrm{C}$ for $4 \mathrm{~d}$ and observed under a stereoscope to remove fragments of substratum and calcareous deposits produced by other organisms. The low drying temperature was selected to avoid phase transitions in the skeletal aragonite/calcite composition (Vongsavat et al. 2006), under investigation in these samples by diffractometric analyses (Goffredo et al. 2012b). Polyp length (L: maximum axis of the oral disk, Fig. 1b), width (W: minimum axis of the oral disk), and height (h: oralaboral axis) were measured with Vernier calipers (Metrica, Milano, Italy). The dry skeletal mass (M) was measured with a digital precision balance. The number of annual growth bands was counted in approximately 30 skeletons randomly selected from each population, to obtain an empirical relationship between size and age. The selected samples were subjected to computerized tomography (CT) for growth band counts, as some forms of scleractinian corals (such as temperate corals) record two annual growth bands in their skeletons, a high-density band in winter and a low-density band in summer (Dodge et al. 1974; Goffredo et al. 2008, 2010; Caroselli et al. 2012; Fig. 1c, d). 
Fig. 1 Caryophyllia inornata: a living polyp; b corallite. Dotted line indicates polyp length ( $L$ maximum axis of the oral disk); c computerized tomography (CT) scan of a mature corallite $(8 \mathrm{yr})$; $\mathbf{d} \mathrm{CT}$ scan of a juvenile corallite (3 yr). The multiple CT views facilitated the recognition of high-density bands (h)
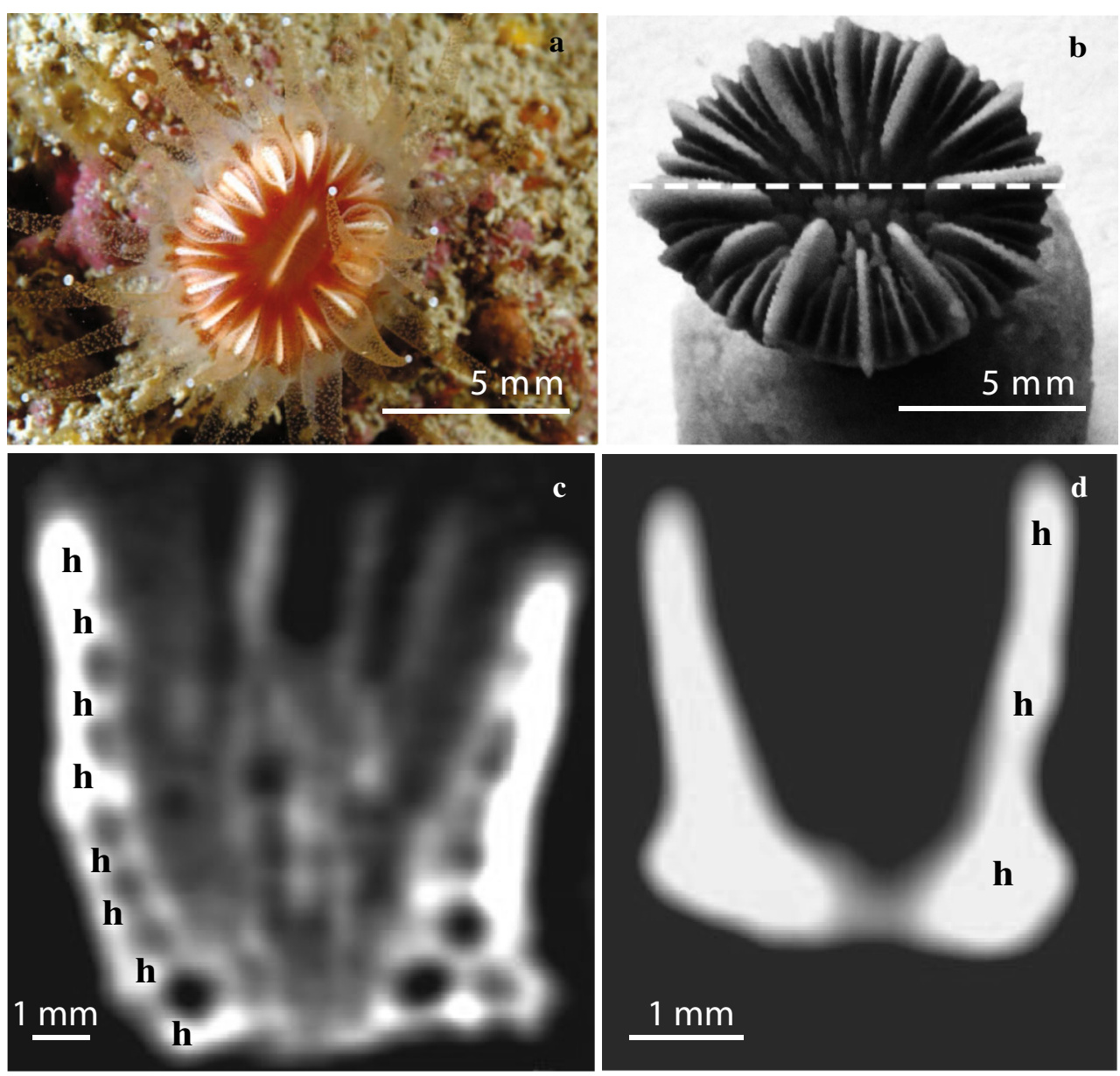

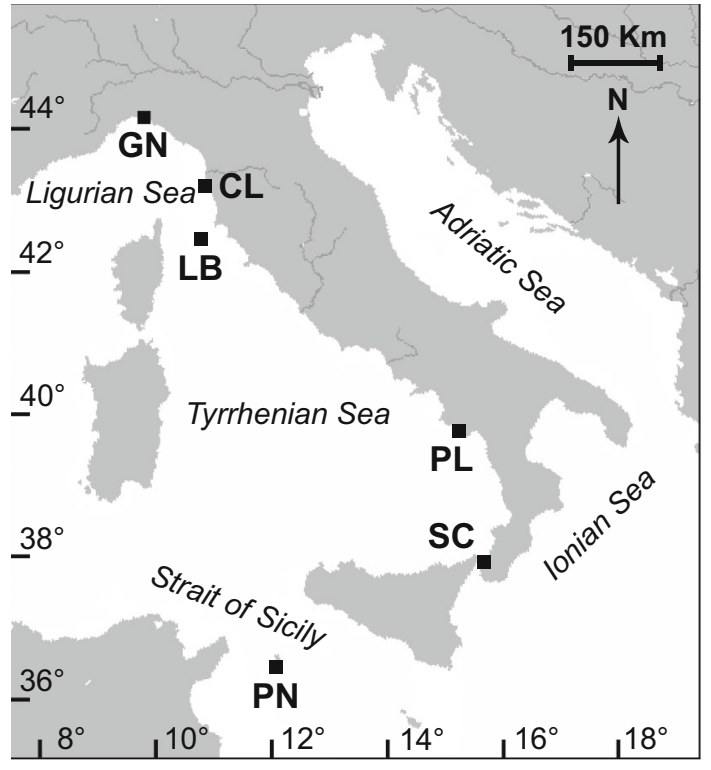

Fig. 2 Map of the Italian coastline indicating sites where samples were collected. $G N$ Genova, $44^{\circ} 20^{\prime} \mathrm{N}, 9^{\circ} 08^{\prime} \mathrm{E} ; C L$ Calafuria, $43^{\circ} 27^{\prime} \mathrm{N}$, $10^{\circ} 21^{\prime} \mathrm{E}$; $L B$ Elba Isle, $42^{\circ} 45^{\prime} \mathrm{N}, 10^{\circ} 24^{\prime} \mathrm{E} ; P L$ Palinuro, $40^{\circ} 02^{\prime} \mathrm{N}$, $15^{\circ} 16^{\prime} \mathrm{E}$; $S C$ Scilla, $38^{\circ} 01^{\prime} \mathrm{N}, 15^{\circ} 38^{\prime} \mathrm{E} ; P N$ Pantelleria Isle, $36^{\circ} 45^{\prime} \mathrm{N}$, $11^{\circ} 57^{\prime} \mathrm{E}$

\section{Growth and population demography modeling}

The age of each scanned individual was obtained using CT (Fig. 1c, d), and the mean annual growth rate was estimated by dividing a polyp's length by its age. As for other Mediterranean solitary corals (Goffredo et al. 2008; Caroselli et al. 2012), the mean annual growth rate showed an exponential negative relationship with individual age (Fig. 3), as required for the application of the von Bertalanffy growth model (von Bertalanffy 1938):

$L_{t}=L_{\infty}\left(1-e^{-k t}\right)$

where $L_{t}$ is individual length at age $t, L_{\infty}$ is the asymptotic length (maximum expected length in the population), $k$ is a growth constant (larger for fast growth up to the asymptotic length, smaller for slow growth), and $t$ is the age of the individual. To apply this growth model, $L_{\infty}$ and $k$, along with their confidence intervals $(\mathrm{CI})$, were estimated for each population through a regression analysis by least squares procedure developed in the software MATLAB R2012a (MathWorks, Natick, USA), since this method has superior fitting properties (Sparre and Venema 1998) than traditional methods (e.g., Pauly 1984). The obtained von 
Table 1 Depth temperature (DT), mean annual solar radiation (SR), number of patches and collected samples, asymptotic length $\left(L_{\infty}\right)$, growth constant $(k)$, coefficient of determination of the semilog regression of Eq. 2, which is an estimator of population structure stability $\left(r^{2}\right)$ and demographic parameters of each population

\begin{tabular}{|c|c|c|c|c|c|c|c|}
\hline \multirow[t]{2}{*}{ Variable } & \multicolumn{7}{|l|}{ Site } \\
\hline & Genova & Calafuria & Elba & Palinuro & Scilla & Pantelleria & General \\
\hline Code & GN & CL & LB & PL & $\mathrm{SC}$ & $\mathrm{PN}$ & \\
\hline $\begin{array}{l}\mathrm{DT}\left({ }^{\circ} \mathrm{C}\right) \text {, annual } \\
\text { mean }(\mathrm{SE})\end{array}$ & $18.24(0.45)$ & $16.74(0.38)$ & $17.63(0.38)$ & $18.94(0.44)$ & $18.20(0.41)$ & $19.15(0.41)$ & \\
\hline $\begin{array}{l}\mathrm{SR}\left(\mathrm{W} \mathrm{m}^{-2}\right) \\
\text { annual mean } \\
(\mathrm{SE})\end{array}$ & $161.8(9.3)$ & 174.9 (10.6) & 183.4 (10.6) & $194.9(10.8)$ & $203.2(10.4)$ & $214.2(10.1)$ & \\
\hline $\begin{array}{l}\text { Number of } \\
\text { patches }\end{array}$ & 6 & 8 & 4 & 6 & 6 & 7 & \\
\hline $\begin{array}{l}\text { Number of } \\
\text { samples } \\
\text { collected }\end{array}$ & 86 & 62 & 241 & 93 & 47 & 39 & \\
\hline $\begin{array}{l}L_{\infty}(\mathrm{mm})(95 \% \\
\text { confidence } \\
\text { limit })\end{array}$ & $21.9(0.0-56.7)$ & $7.1(3.8-10.4)$ & $\begin{array}{l}22.5 \\
\quad(12.1-32.9)\end{array}$ & $\begin{array}{l}22.5 \\
\quad(10.2-34.7)\end{array}$ & $12.3(6.9-17.6)$ & $\begin{array}{l}16.1 \\
\quad(11.4-20.9)\end{array}$ & $\begin{array}{l}15.8 \\
\quad(13.1-18.5)\end{array}$ \\
\hline $\begin{array}{l}k \text { (95\% } \\
\text { confidence } \\
\text { limit) }\end{array}$ & $\begin{array}{l}0.048 \\
\quad(0.000-0.099)\end{array}$ & $\begin{array}{l}0.234 \\
\quad(0.035-0.432)\end{array}$ & $\begin{array}{l}0.041 \\
\quad(0.017-0.066)\end{array}$ & $\begin{array}{l}0.048 \\
\quad(0.015-0.082)\end{array}$ & $\begin{array}{l}0.101 \\
\quad(0.022-0.180)\end{array}$ & $\begin{array}{l}0.073 \\
\quad(0.040-0.105)\end{array}$ & $\begin{array}{l}0.072 \\
\quad(0.054-0.090)\end{array}$ \\
\hline$r^{2}$ & 0.803 & 0.853 & 0.829 & 0.523 & 0.437 & 0.449 & \\
\hline $\begin{array}{l}\text { Instantaneous } \\
\text { rate of } \\
\text { mortality } \\
Z \text { (95\% } \\
\text { confidence } \\
\text { limit) }\end{array}$ & $\begin{array}{l}0.354 \\
\quad(0.180-0.530)\end{array}$ & $\begin{array}{l}0.541 \\
\quad(0.283-0.799)\end{array}$ & $\begin{array}{l}0.223 \\
\quad(0.156-0.290)\end{array}$ & $\begin{array}{l}0.136 \\
\quad(0.058-0.259)\end{array}$ & $\begin{array}{l}0.102 \\
\quad(0.014-0.190)\end{array}$ & $\begin{array}{l}0.081 \\
\quad(0.013-0.149)\end{array}$ & \\
\hline $\begin{array}{l}\text { Observed } \% \text { of } \\
\text { immature } \\
\text { individuals }\end{array}$ & 81.4 & 95.2 & 58.9 & 39.8 & 42.6 & 38.5 & \\
\hline $\begin{array}{l}\text { Theoretical\% of } \\
\text { immature } \\
\text { individuals }\end{array}$ & 91.9 & 98.0 & 79.3 & 67.3 & 51.3 & 43.4 & \\
\hline $\begin{array}{l}\text { Observed mean } \\
\text { age }(\mathrm{yr})(95 \% \\
\text { confidence } \\
\text { limit) }\end{array}$ & $4.6(4.0-5.1)$ & $3.3(2.9-3.7)$ & $6.5(6.0-7.0)$ & $8.5(7.7-9.2)$ & $8.3(7.2-9.4)$ & $8.8(7.5-10.1)$ & \\
\hline $\begin{array}{l}\text { Theoretical } \\
\text { mean age (yr) }\end{array}$ & 2.3 & 1.4 & 3.9 & 5.7 & 9.1 & 11.6 & \\
\hline $\begin{array}{l}\text { Observed age at } \\
\max \% \text { of } \\
\text { biomass (yr) }\end{array}$ & 5 & 2 & 11 & 10 & 10 & 15 & \\
\hline $\begin{array}{l}\text { Theoretical age } \\
\text { at max\% of } \\
\text { biomass (yr) }\end{array}$ & 6 & 4 & 9 & 11 & 15 & 18 & \\
\hline $\begin{array}{l}\text { Observed mean } \\
\text { age of biomass } \\
(\mathrm{yr})\end{array}$ & 6.7 & 4.4 & 10.2 & 10.8 & 11.1 & 11.5 & \\
\hline $\begin{array}{l}\text { Theoretical } \\
\text { mean age of } \\
\text { biomass (yr) }\end{array}$ & 7.7 & 4.9 & 11.7 & 14.8 & 21.1 & 25.3 & \\
\hline
\end{tabular}

Bertalanffy age-length relationship was used to estimate the age of all samples for which CT scans were not performed.
The theoretical population age structure and the population age structure stability were estimated by a linear regression analysis of the natural logarithm of the number 


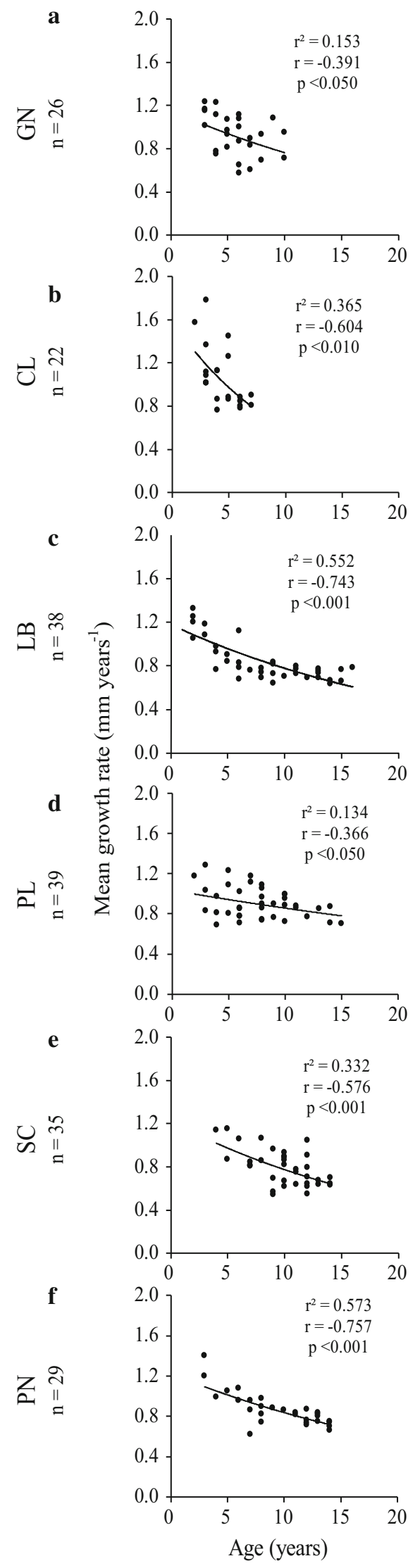

4 Fig. 3 Relationship between mean growth rate and individual age at a Genova, b Calafuria, c Elba Isle, d Palinuro, e Scilla, f Pantelleria Isle. Data were fitted with exponential curves to verify the assumptions of the von Bertalanffy growth model. $n=$ number of individuals dated by computerized tomography (CT) scans

of individuals (frequency) in each age class $\left(N_{t}\right)$ against their corresponding age $(t)$ :

$\ln \left(N_{t}\right)=a t+b$

where $a$ is the slope, indicated also with sign changed as $Z$ (instantaneous rate of mortality), which represents the decrement of the number of individuals with age and is the reciprocal of the turnover time of the population (Pauly 1984; Goffredo and Chadwick-Furman 2003; Goffredo et al. 2010). The intercept $b$ corresponds to the natural logarithm of the number of individuals at age zero $\left(N_{0}\right)$ (Pauly 1984; Caroselli et al. 2012). In a theoretical steadystate population (i.e., no age cohort missing or overrepresented, as would be the case if a major disturbance event had recently altered recruitment patterns; Grigg 1984), $100 \%$ of the variance in the frequency of age classes is explained by age and the $r^{2}$ of the regression line of Eq. 2 is equal to one. Populations deviating from the steady state will have lower $r^{2}$ values (Sparre et al. 1989; Goffredo et al. 2004; Caroselli et al. 2012).

The Beverton and Holt model was applied to describe the population dynamics of $C$. inornata in each population and to obtain the theoretical population parameters (Beverton and Holt 1956; Chadwick-Furman et al. 2000; Goffredo et al. 2008, 2010; Goffredo and Lasker 2008; Caroselli et al. 2012). Population age structures sampled in the field are usually underrepresented in the younger age classes, as smaller individuals are difficult to observe and collect in situ while diving. The "theoretical" population obtained with the Beverton and Holt demographic model also reconstructs the youngest age classes and is an additional estimation of population demographic traits. The observed mean age of the individuals at each site was computed from the age of collected samples dated with the growth curve (Eq. 1). The theoretical mean age was estimated as that of the theoretical number of individuals at each site. The observed percentage of individuals below sexual maturity was obtained by summing the frequencies of the age classes below sexual maturity, which is $\sim 8 \mathrm{yr}$ ( $\sim 6.1 \mathrm{~mm}$ length; Marchini et al. 2015). The theoretical percentage of individuals below sexual maturity was determined by summing the frequencies of the theoretical number of individuals in the age classes below sexual maturity at each site. The observed biomass distribution per age class was obtained by the sum of each corallite mass in each age class. The theoretical biomass distribution per age 
class was then obtained by multiplying the theoretical number of individuals in each age class for the expected biomass at that age. The observed age at maximum percentage biomass was estimated as the age class representing the highest percentage biomass, using the observed biomass distribution. The theoretical age at maximum percentage biomass was determined in the same way, using the theoretical distribution. The observed mean age of biomass in the populations was calculated as the sum of the products of the observed biomass in each age class multiplied by its age and then divided by the total observed biomass. The theoretical mean age of biomass in each site was calculated in the same way, but using the theoretical biomass.

\section{Temperature and solar radiation}

In this study, for each site, environmental parameters (DT and SR) were collected for a period equal to the mean turnover time of populations, which was $6 \mathrm{yr}$ (calculated as the reciprocal of the instantaneous rate of mortality, $Z$ ). Thus, for each site, 72 average monthly values of DT and SR were collected for the $6 \mathrm{yr}$ prior to the month of sampling. With this method, the mean values of environmental parameters considered were those experienced by the polyps for most of their lifespan. Data were obtained from data banks, as commonly done to study the influence of environmental parameters on coral growth (e.g., Harriott 1999; Peirano et al. 1999, 2005; Lough and Barnes 2000; Carricart-Ganivet 2004; Cantin et al. 2010).

Temperature data $\left({ }^{\circ} \mathrm{C}\right)$ were recorded every $2-3 \mathrm{~h}$ by digital thermometers (i-Button, DS1921G-F5\#, Maxim Integrated Products, Dallas Semiconductors) placed at the experimental sites to record seawater temperature over time intervals that varied by site. Thermometers were replaced every 3 months to avoid problems of encrustation and overgrowth by marine organisms. SST historical data $\left({ }^{\circ} \mathrm{C}\right)$ were obtained for each site from the National Mareographic Network of the Superior Institute for Environmental Protection and Research (ISPRA; http://isprambiente.gov.it). These data are measured by SM3810 mareographic stations located close to the sampling sites and provided by the Society for Environmental and Industrial Monitoring (SIAP + MICROS). For each site, historical at-depth temperatures were estimated by linear regression between DT and SST. In this study, the average DT of the $6 \mathrm{yr}$ preceding sampling ( $n=72$ monthly temperatures) was considered.

Monthly values of SR $\left(\mathrm{W} \mathrm{m}^{-2}\right)$ were obtained from the data bank of the Satellite Application Facility on Climate Monitoring (CM-SAF/EUMETSAT; http://www.cmsaf. eu). These are estimates derived from real-time satellite measurements and datasets registered with intersensor calibrated radiances. Mean annual solar radiation was calculated for the $15 \mathrm{~km}$ square associated with each study site by averaging 72 monthly values for each site.

\section{Statistical analyses}

An analysis of variance (ANOVA) was used to compare the mean DT and SR among the six sites, after checking that the assumptions for parametric statistics were fulfilled. Pearson's correlation coefficients were calculated between physical parameters (DT and SR) and population parameters, namely instantaneous rate of mortality $(Z)$, population structure stability $\left(r^{2}\right)$, observed and theoretical percentage of individuals below sexual maturity, observed and theoretical mean age, observed and theoretical age at maximum percentage of biomass, and observed and theoretical mean age of biomass. Pearson's correlation coefficients were also calculated with a bootstrapping procedure (1000 resamples) for a more careful and reliable analysis (Efron 1981). A nonparametric KolmogorovSmirnov test was used to test for differences in the age frequencies of the six populations. All analyses were done using SPSS Statistics 22.

\section{Results}

The mean annual values of SR ranged from $161.8 \mathrm{~W} \mathrm{~m}^{-2}$ at $\mathrm{GN}$ to $214.2 \mathrm{~W} \mathrm{~m}^{-2}$ at PN (Table 1). Mean annual values of DT ranged from $16.74{ }^{\circ} \mathrm{C}$ at $\mathrm{CL}$ to $19.15^{\circ} \mathrm{C}$ at PN (Table 1). Mean SR and DT were significantly different among sites (ANOVA, $p<0.01$ ). While SR decreased with higher latitude, DT did not correlate with latitude (Fig. 4).

Each population showed an exponential decrease in mean growth rate with increasing age, with age variance explaining 13-57\% of mean growth rate variation (Fig. 3). Mean growth rate decreased from $0.8-1.2 \mathrm{~mm} \mathrm{yr}^{-1}$ for immature individuals $(0-7 \mathrm{yr})$ to $0.5-0.7 \mathrm{~mm} \mathrm{yr}^{-1}$ for mature individuals (7-14 yr; Fig. 3).

$L_{\infty}$ and $k$ for each population were homogeneous among sites (95\% CI overlapped; Table 1); therefore, data from all the individuals dated by growth bands in all populations were pooled. The general $L_{\infty}$ and $k$ values were then estimated (Table 1) to obtain a general von Bertalanffy growth curve (Fig. 5) describing the age-length relationship across all sampling sites. All $95 \%$ CI of $k$ values for each population overlapped with the $95 \% \mathrm{CI}$ of the general $k$ value (Table 1 ). The $95 \%$ CI of $L_{\infty}$ of the CL population did not overlap with the $95 \%$ CI of the general $L_{\infty}$ value (Table 1). However, for the CL population, the difference between the age of each sample estimated with the general growth curve and that estimated with the CL growth curve had a mean of $0.060 \mathrm{yr}$ and a $95 \% \mathrm{CI}$ in the 

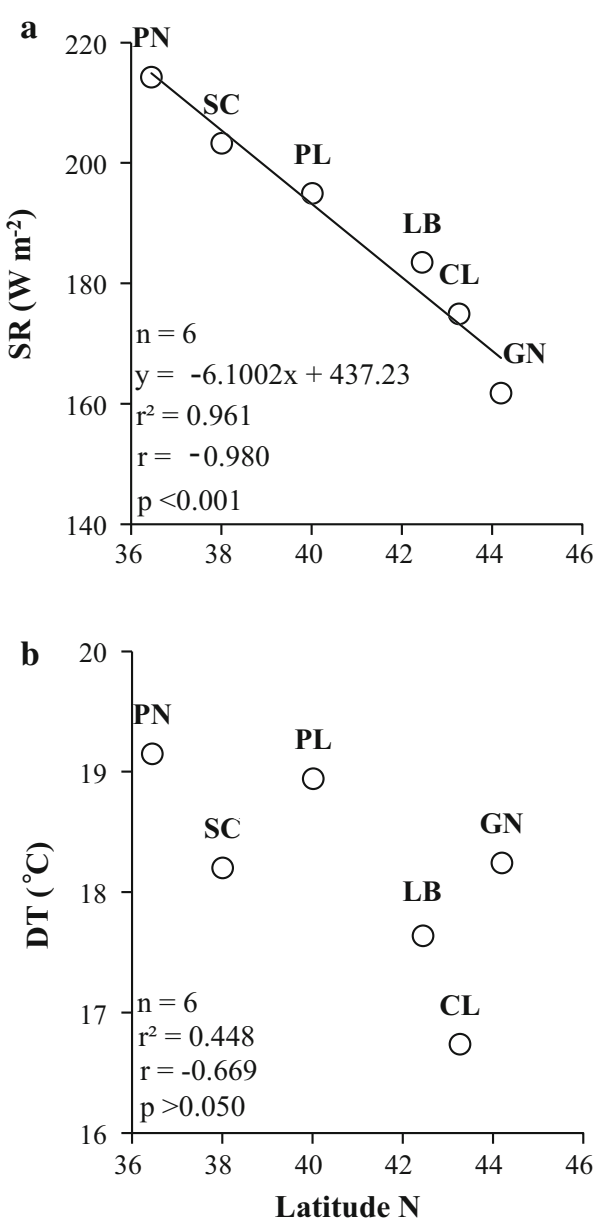

Fig. 4 Relationships between latitude and a solar radiation (SR) and b depth temperature (DT) at study sites (GN Genova, $C L$ Calafuria, $L B$ Elba Isle, $P L$ Palinuro, $S C$ Scilla, $P N$ Pantelleria Isle). $n=$ number of sites; $r=$ Pearson's correlation coefficient

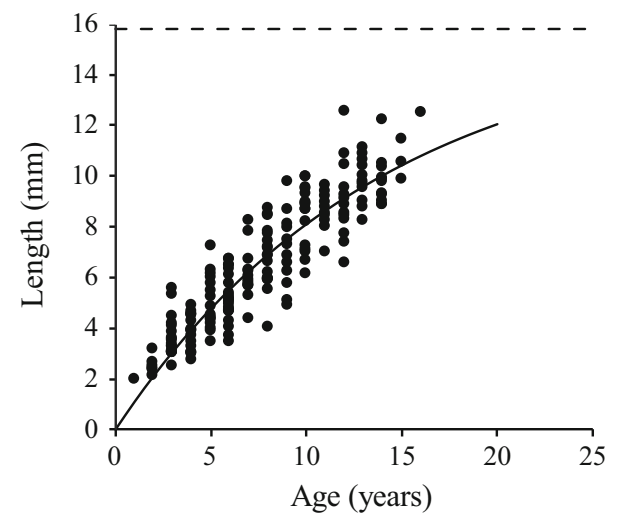

Fig. 5 General age-length von Bertalanffy growth curve (see Eq. 1) describing the growth in all populations. Dotted line indicates the maximum expected length of corals in all populations $\left(L_{\infty}=15.8 \mathrm{~mm}\right)$. Points indicate the age/size of all samples in all populations, dated by computerized tomography (CT) scans $(n=189)$ from which the general growth curve was obtained range -0.324 to $0.444 \mathrm{yr}$ (i.e., containing zero), indicating that the difference in the age estimated by the two curves was negligible. Moreover, for the CL population, the difference between the age of each sample estimated with the general growth curve and the one obtained by growth band counts had a mean of $0.111 \mathrm{yr}$ and a $95 \% \mathrm{CI}$ in the range -0.348 to $0.570 \mathrm{yr}$ (i.e., containing zero), indicating that the general growth curve was a good estimator of coral age at CL. All 568 individuals collected were dated using the general growth curve (Eq. 1; Fig. 5). The oldest individual came from the Scilla population (SC) with an estimated age of $22 \mathrm{yr}$ and a length of $12.55 \mathrm{~mm}$.

The age-frequency distributions (Fig. 6) differed among populations (Kolmogorov-Smirnov test, $p<0.001$ ). The observed and theoretical population demographic parameters are given in Table 1 and shown in Fig. 6. Based on the bootstrapping correlation coefficients, the instantaneous rate of mortality $(Z$, ranging from 0.541 at $\mathrm{CL}$ to 0.081 at PN; Table 1), population structure stability $\left(r^{2}\right.$, ranging from 0.803 at $\mathrm{GN}$ to 0.437 at $\mathrm{SC}$; Table 1 ), and observed and theoretical percentage of individuals below sexual maturity (ranging from $95.2 \%$ at CL to $38.5 \%$ at PN, and $98.0 \%$ at CL to $43.4 \%$ at PN, respectively; Table 1) were negatively correlated with SR (decreasing southward), while the observed and theoretical mean age (ranging from $3.3 \mathrm{yr}$ at CL to $8.8 \mathrm{yr}$ at PN, and $1.4 \mathrm{yr}$ at CL to $11.6 \mathrm{yr}$ at PN, respectively; Table 1) and theoretical age at maximum percentage of biomass (ranging from $4 \mathrm{yr}$ at CL to $18 \mathrm{yr}$ at PN; Table 1) were positively correlated with SR (increasing southward; Table 2). No demographic parameter was correlated with DT.

\section{Discussion}

In all populations along the investigated latitudinal gradient, $C$. inornata showed determinate growth, characterized by a decreasing growth rate with increasing age, as previously demonstrated in other animals (Sebens 1987). Latitudinal variation in environmental conditions can affect the size of organisms (Lough and Barnes 2000), influencing coral growth rate and maximum size within the limits allowed by the organism's biology (Carricart-Ganivet 2004; Cantin et al. 2010). Determinate growth is a characteristic of some colonial octocorals (Goffredo and Lasker 2008) and scleractinians, such as branching Pocillopora spp. (Grigg and Maragos 1974), massive Goniastrea aspera (now renamed as Coelastrea aspera; Sakai 1998; Huang et al. 2014), and free-living Manicina areolata (Johnson 1992), but this characteristic is mainly found in solitary corals, such as B. europaea (Goffredo et al. 2008), B. elegans, Paracyathus stearnsii (Gerrodette 1979), L. pruvoti (Goffredo et al. 2010; Caroselli et al. 2012), the 
Fig. 6 Age class structures by abundance and proportion of biomass of populations of Caryophyllia inornata at a Genova, b Calafuria, c Elba Isle, d Palinuro, e Scilla,

f Pantelleria Isle. The lines indicate the theoretical distributions. The observed (grey column) and theoretical (black square) age classes containing the mean age of the individuals of sampled population are indicated. The observed age at maximum percentage biomass (black column) and theoretical (black circle) age at maximum percentage biomass are indicated. Asterisks indicate the age at sexual maturity
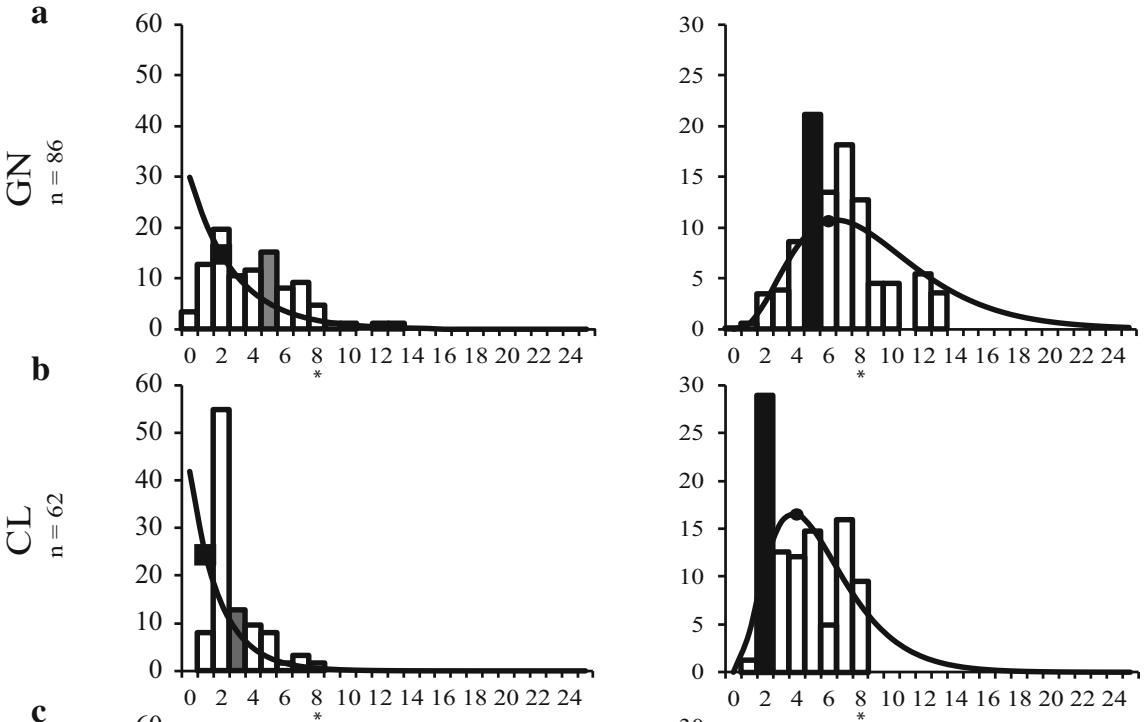

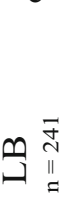

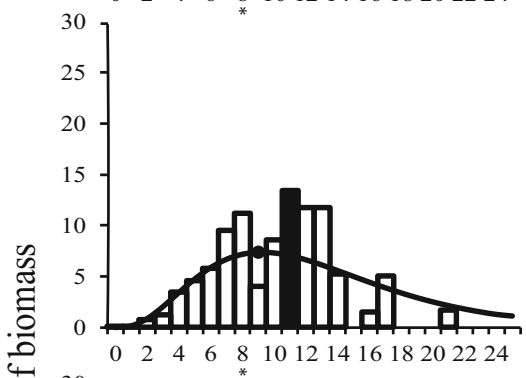

d

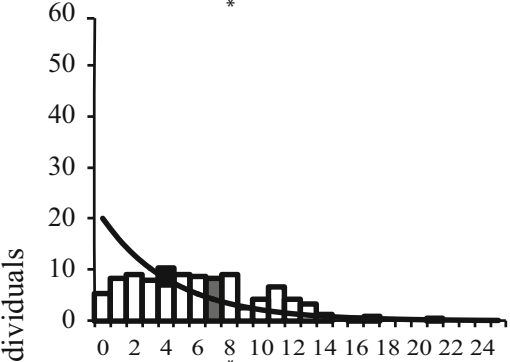

2 aे

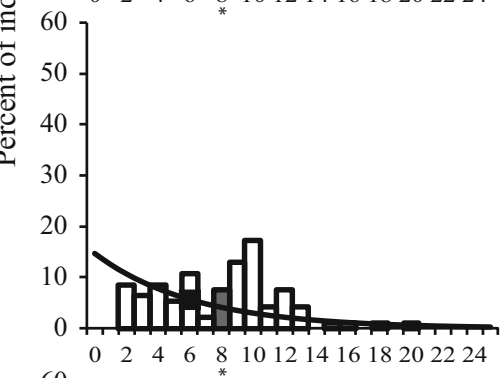

e

e
$\bigcup_{\sim} \stackrel{\text { }}{=}$
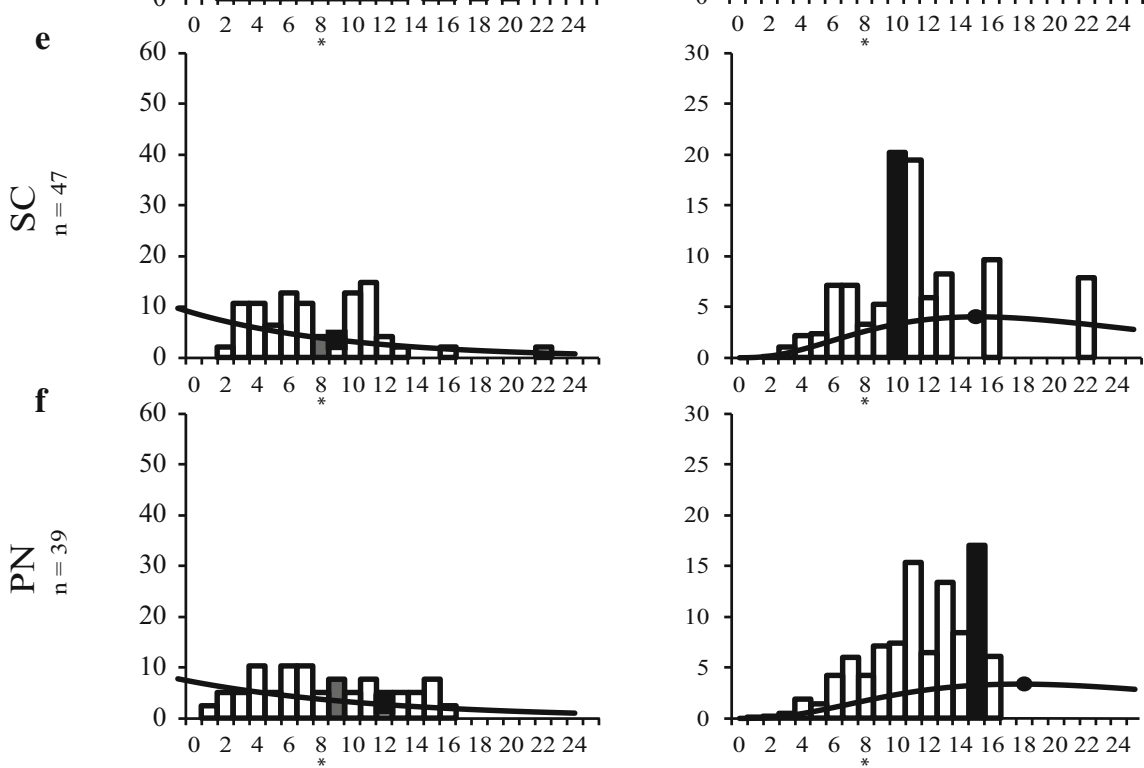

Age (years) 
Table 2 Correlation analyses between solar radiation and depth temperature (independent variables) and demographic parameters (dependent variables) in the sampled populations ( $n=6$ sites)

\begin{tabular}{|c|c|c|c|c|c|}
\hline & $n$ & $r^{2}$ & $r$ & $r_{\mathrm{BS}}^{2}$ & $r_{\mathrm{BS}}$ \\
\hline \multicolumn{6}{|l|}{ Solar radiation } \\
\hline Instantaneous rate of mortality $(Z)$ & 6 & 0.654 & $-0.883^{*}$ & 0.759 & $-0.871^{*}$ \\
\hline Population structure stability $\left(r^{2}\right)$ & 6 & 0.778 & -0.809 & 0.759 & $-0.871^{*}$ \\
\hline Observed\% of individuals below sexual maturity & 6 & 0.744 & $-0.862 *$ & 0.785 & $-0.886^{*}$ \\
\hline Theoretical $\%$ of individuals below sexual maturity & 6 & 0.899 & $-0.949 * *$ & 0.906 & $-0.952 * *$ \\
\hline Observed mean age & 6 & 0.768 & $-0.876^{*}$ & 0.794 & $0.891^{*}$ \\
\hline Theoretical mean age & 6 & 0.883 & $0.939 * *$ & 0.889 & $0.943 * *$ \\
\hline Observed age at maximum $\%$ of biomass & 6 & 0.687 & $0.829 *$ & 0.643 & 0.802 \\
\hline Theoretical age at maximum $\%$ of biomass & 6 & 0.878 & $0.937 * *$ & 0.874 & $0.935^{* *}$ \\
\hline Observed mean age of biomass & 6 & 0.657 & 0.811 & 0.740 & $0.860^{*}$ \\
\hline Theoretical mean age of biomass & 6 & 0.877 & $0.937 * *$ & 0.884 & $0.940 * *$ \\
\hline \multicolumn{6}{|l|}{ Depth temperature } \\
\hline Instantaneous rate of mortality $(Z)$ & 6 & 0.690 & -0.769 & 0.558 & -0.743 \\
\hline Population structure stability $\left(r^{2}\right)$ & 6 & 0.592 & -0.830 & 0.552 & -0.747 \\
\hline Observed\% of individuals below sexual maturity & 6 & 0.654 & -0.809 & 0.587 & -0.766 \\
\hline Theoretical\% of individuals below sexual maturity & 6 & 0.555 & -0.745 & 0.483 & -0.695 \\
\hline Observed mean age & 6 & 0.674 & $-0.821^{*}$ & 0.598 & 0.773 \\
\hline Theoretical mean age & 6 & 0.526 & 0.725 & 0.489 & 0.699 \\
\hline Observed age at maximum $\%$ of biomass & 6 & 0.564 & 0.751 & 0.387 & 0.622 \\
\hline Theoretical age at maximum $\%$ of biomass & 6 & 0.565 & 0.751 & 0.491 & 0.701 \\
\hline Observed mean age of biomass & 6 & 0.579 & 0.761 & 0.483 & 0.695 \\
\hline Theoretical mean age of biomass & 6 & 0.555 & 0.745 & 0.497 & 0.705 \\
\hline
\end{tabular}

free-living deep coral Flabellum alabastrum (Hamel et al. 2010), and the free-living fungiids Diaseris distorta (now renamed as Cycloseris distorta; Yamashiro and Nishihira 1998; Gittenberger et al. 2011), Ctenactis echinata, Fungia scutaria (now renamed as Lobactis scutaria; Gittenberger et al. 2011), F. fungites, the subgenus Fungia (Danafungia) spp. (now renamed as Danafungia spp.; Goffredo and Chadwick-Furman 2003; Gittenberger et al. 2011), and Heliofungia actiniformis (Knittweis et al. 2009). The growth rate of colonies or single polyps can be affected by several environmental factors and differs greatly among scleractinians (Chornesky and Peters 1987; Goffredo et al. 2008; Caroselli et al. 2012; Kružić et al. 2012). Measurements of growth in natural populations refer mostly to zooxanthellate scleractinians, while only few studies have focused on non-zooxanthellate species. Exceptions include studies on deepwater Lophelia pertusa (Gass and Roberts 2006), temperate B. regia from the French Atlantic coast (Brahmi et al. 2010), and L. pruvoti from the Mediterranean Sea (Caroselli et al. 2012). Since the age-length relationships of $C$. inornata were homogeneous among sites, a general growth curve was obtained (Fig. 5) to describe the growth of individuals across the whole
Mediterranean latitudinal range of this species. It must be noted that the species range also extends to the Atlantic, where environmental conditions are very different and growth could respond differently to latitudinal gradients. Growth rates estimated in this study agree with the only previous study of growth in this species, from Spain (Teixidó et al. 2011). In the Mediterranean Sea, the latitudinal variation of temperature greatly influences the population characteristics of some scleractinian corals (Goffredo et al. 2008; Kružić et al. 2012; Airi et al. 2014; Caroselli et al. 2015b), even though some exceptions have been reported. Previous studies on solitary scleractinians living in the same sites and analyzed using the same methods as in the present study showed homogeneous growth for the non-zooxanthellate L. pruvoti along the same latitudinal gradient (Caroselli et al. 2012), while in the zooxanthellate $B$. europaea, $k$ decreased and $L_{\infty}$ increased with increasing temperature (Goffredo et al. 2008). The apparent insensitivity of the growth of $C$. inornata and L. pruvoti (i.e., homogeneous growth parameters) to SR and temperature variations along the latitudinal gradient may be explained by their biology and/ or ecological mechanisms: (1) the lack of photosynthetic 
symbionts, which generally stimulate calcification and growth in zooxanthellate corals (Al-Horani 2005; Goffredo et al. 2009) and lower their photosynthetic efficiency when exposed to excessive temperature (Al-Horani 2005); (2) a wide range of optimal temperatures for calcification in this species; (3) synergies between 1 and 2; or (4) a notable adaptation capability of these species to environmental conditions. Assessment of demographic characteristics provided new insights into these hypotheses.

The lack of significant correlation between demographic parameters and DT was expected. Temperature is an important environmental parameter whose latitudinal variation influences the biometry, abundance, growth, and demography of some Mediterranean zooxanthellate corals (Goffredo et al. 2007, 2008, 2009), while the only asymbiotic scleractinian studied in the Mediterranean (L. pruvoti) seemed unaffected by temperature differences among sites (Caroselli et al. 2012). However, any comparison between $C$. inornata and B. europaea must be interpreted cautiously, since the two species were sampled at different depths ( $\sim 14$ and $\sim 6 \mathrm{~m}$, respectively) that may be subjected to slightly different thermal regimes throughout the year. Calcification is depressed when temperature is outside of the species-specific optimal range (Howe and Marshall 2002). A recent study indicated that $C$. inornata calcification was unaffected by temperature differences along the same Mediterranean latitudinal gradient investigated in this study (Caroselli et al. unpublished). The calcification tolerance to a wide range of temperature as observed in the non-zooxanthellate $L$. pruvoti studied at the same sites (Caroselli et al. 2012) may be due to the absence of symbiotic zooxanthellae, which need appropriate temperatures for regular metabolism (Carricart-Ganivet et al. 2012). Supporting the possible high adaptation capability of $C$. inornata to latitudinal variation in temperature, the Caryophylliidae family (Dana 1846) is widespread from shallow (Cairns et al. 2005) to deep waters (Squires 1959), from coastal Antarctic (Cairns 1982) to the Arctic Circle (Roberts et al. 2003), and Caryophyllia is the most diverse genus within non-zooxanthellate scleractinians (Kitahara et al. 2010).

Unexpectedly, most of the parameters of this nonzooxanthellate species analyzed were significantly correlated with SR along the investigated Mediterranean latitudinal range. The stability of population structure $\left(r^{2}\right.$ of Eq. 2), the instantaneous rate of mortality ( $Z$ ), and the percentage of immature individuals decreased with increasing SR (southward) (Table 1). In addition, the average age of populations (from $4.6 \mathrm{yr}$ for the northernmost site, GN, to $8.8 \mathrm{yr}$ for the southernmost, PN), the mean age of biomass (from 6.7 at GN to 11.5 at PN), and the age at maximum biomass (from $5 \mathrm{yr}$ at GN to $15 \mathrm{yr}$ at PN) increased with increasing SR (Tables 1,2). All these correlations indicate that with increasing SR (southward), populations were less stable and presented deficits of young individuals. This trend strictly refers to the investigated latitudinal range in the Mediterranean Sea and cannot predict the response of Atlantic populations, which could be very different. Since this species is non-zooxanthellate, SR is likely to have no direct effect on the species, but the SR latitudinal gradient could be related to other abiotic and/or biotic parameters that were not investigated in this study. For example, plankton in seawater of the western Mediterranean Sea decreases moving southward (D'Ortenzio and Ribera d'Alcalà 2009). The wind effect, winter layers mixing, and coastal upwelling create a biomass gradient for phyto- and zooplankton from north to south along the western Italian coastline (D'Ortenzio and Ribera d'Alcalà 2009). Low presence of zooplankton may cause feeding deficits and reduced available energy for polyps (Coma and Ribes 2003; Leuzinger et al. 2012); thus, the observed deficit of immature individuals could be related to an energetic trade-off between growth and reproduction (Kozłowski and Wiegert 1986). The reduced stability and deficit of immature individuals in southern populations (high SR) could be explained through the allocation of energy to growth at the expense of reproduction. While there are few studies on energy allocation of shallow non-zooxanthellate corals under energetic deficit, there are several studies on zooxanthellate species. Tropical Montipora digitata subjected to low light regime (and thus energetic depletion) for $1 \mathrm{yr}$ showed a reduced growth rate, while the energy allocation for reproduction increased at intermediate levels of resource availability, ceasing completely only at the lowest resource availability (Leuzinger et al. 2012). Populations of Mediterranean $B$. europaea showed reduced $k$ growth constant with increasing temperature (Goffredo et al. 2008), probably due to the inhibition of photosynthesis by zooxanthellae, which reduced the availability of energy (Caroselli et al. 2015a). Growth rate decreased in populations of Orbicella sp. characterized by high temperatures (Carricart-Ganivet 2004), while species of Porites (Lough and Barnes 2000), Acropora, and Pocillopora (Crossland 1981) showed the opposite growth trend. Caryophyllia inornata growth parameters do not correlate with environmental gradients; thus, skeletal deposition seems unaffected by temperature and light regime, while reproduction could be affected. The species may reduce energetic investment in reproductive output in favor of growth as a response to the zooplankton deficit. This could explain the lack of immature corals in the southernmost populations, suggesting a correlation between SR and abundance along the investigated latitudinal gradient. However, a recent study at the same sites showed that population abundance was not correlated with SR (Caroselli et al. 2015b). This could depend on the lower 
mortality rate $(Z)$ in the southernmost populations; the deficit of young individuals could be counterbalanced by the decreasing morality rate, resulting in the observed homogeneous abundance across sites. As an alternative hypothesis, the deficit of immature individuals in southern populations of the Mediterranean Sea could be related to larval vicariance as a result of the marine flow that follows the western Italian coastline from south to north throughout the year (Istituto Idrografico della Marina 1982). The northern Italian populations may benefit from the flow of larvae from north-flowing currents, while southern populations cannot benefit from the same effect because they lie on the southern border of the species' distribution ( $\mathrm{Zi}$ browius 1980). However, the relevance of this effect also depends on the competency period of the planulae, which is affected by the reproductive mode. Brooding corals such as $C$. inornata (Goffredo et al. 2012a) tend to have larvae that rapidly reach competency relative to broadcastspawning corals (Jackson 1986; Harrison and Wallace 1990; Goffredo and Zaccanti 2004). However, the larval traits of this species are not known, and further studies on larval behavior are needed to clarify whether larval vicariance could contribute to the observed deficit of young individuals in southern populations. In any case, these data must be interpreted cautiously because the mass mortality in the northwestern Mediterranean Sea in 2003 (RodolfoMetalpa et al. 2006) may have changed the abundance of northern populations and may have biased the analysis.

The demography of $C$. inornata populations showed the same tolerance to temperature recorded for the non-zooxanthellate solitary scleractinian $L$. pruvoti studied at the same sites (Goffredo et al. 2010; Caroselli et al. 2012). Even though $C$. inornata shares several biological features and a tolerance to temperature with $L$. pruvoti, at least at these sites, the trend of demographic parameters with SR differs between the two species. The deficit of immature $C$. inornata polyps with increasing SR may be related to reduced plankton availability, but it contrasts with the lack of trend with SR variations along the latitudinal gradient for L. pruvoti (Caroselli et al. 2012). The different responses of the two species and their different range of population density values $(C$. inornata has an abundance up to ten times lower than L. pruvoti) (Goffredo et al. 2007; Caroselli et al. 2015b) could be explained if $C$. inornata had a more specialist diet than L. pruvoti, resulting in lower availability of resources when zooplankton abundance is depleted. Unfortunately, the feeding strategies of the two species have not yet been investigated, and further analyses are needed to verify this hypothesis.

In conclusion, this research shows that the growth rate of $C$. inornata is homogeneous along a Mediterranean latitudinal gradient covering $2.4{ }^{\circ} \mathrm{C}$ of DT variation and $52 \mathrm{~W} \mathrm{~m}^{-2}$ of SR variation. In this latitudinal range, while population dynamics parameters are uncoupled with DT, they are strongly related to variation in SR, with populations becoming progressively less stable and with fewer young individuals with increasing SR (southward). The implications of SR for demography are attributed to indirect effects of zooplankton availability. Previous studies on Mediterranean solitary corals hypothesized that zooxanthellate species were more sensitive to high temperatures than non-zooxanthellate species. This work suggests that this may be the case for DT, but that non-zooxanthellate species may be negatively affected in their demography by the indirect effects of SR.

Acknowledgments We wish to thank S. Branchini, F. Gizzi, M. Marinozzi, S. Prantoni, and F. Turano for their underwater assistance. The diving centers Centro Immersioni Pantelleria, Il Pesciolino, Bubble Lounge, and Sub Maldive supplied logistics in the field. The Scientific Diving School (www.sdseducational.org) supplied scientific, technical, and logistical support. Coral photographs are provided by G. Neto (www.giannineto.it). We thank H. Matz for manuscript proofreading. The research leading to these results received funding from the European Research Council under the European Union's Seventh Framework Programme (FP7/2007-2013)/ERC Grant Agreement No. [249930-CoralWarm: Corals and global warming: the Mediterranean versus the Red Sea].

\section{References}

Airi V, Gizzi F, Falini G, Levy O, Dubinsky Z, Goffredo S (2014) Reproductive efficiency of a Mediterranean endemic zooxanthellate coral decreases with increasing temperature along a wide latitudinal gradient. PLoS One 9:e91792

Al-Horani FA (2005) Effects of changing seawater temperature on photosynthesis and calcification in the scleractinian coral Galaxea fascicularis, measured with $\mathrm{O}_{2}, \mathrm{Ca}^{2+}$ and $\mathrm{pH}$ microsensors. Sci Mar 69:347-354

Babcock RC (1991) Comparative demography of three species of scleractinian corals using age- and size-dependent classifications. Ecol Monogr 6:225-244

Beverton RJH, Holt SV (1956) A review of methods for estimating mortality rates in fish populations, with special reference to sources of bias in catch sampling. Rapports et Proces-Verbaux des Reunions - Conseil International pour l'Exploration de la Mer 140:67-83

Brahmi C, Meibom A, Smith DC, Stolarski J, Auzoux-Bordenave S, Nouet J, Doumenc D, Djediat C, Domart-Coulon I (2010) Skeletal growth, ultrastructure and composition of the nonzooxanthellate scleractinian coral Balanophyllia regia. Coral Reefs 29:175-189

Brooke S, Young CM (2005) Embryogenesis and larval biology of the ahermatypic scleractinian Oculina varicosa. Mar Biol 146:665-667

Cairns SD (1982) Antarctic and sub Antarctic scleractinia. American Geophysical Union, Washington

Cairns SD, Häussermann V, Försterra G (2005) A review of the Scleractinia (Cnidaria: Anthozoa) of Chile, with the description of two new species. Zootaxa 1018:15-46

Cantin NE, Cohen AL, Karnauskas KB, Tarrant AM, McCorkle DC (2010) Ocean warming slows coral growth in the central Red Sea. Science 329:322-325

Caroselli E, Falini G, Goffredo S, Dubinsky Z, Levy O (2015a) Negative response of photosynthesis to natural and projected 
high seawater temperatures estimated by pulse amplitude modulation fluorometry in a temperate coral. Front Physiol 6:317. doi:10.3389/fphys.2015.00317

Caroselli E, Nanni V, Levy O, Falini G, Dubinsky Z, Goffredo S (2015b) Latitudinal variations in biometry and population density of a Mediterranean solitary coral suggest higher tolerance to seawater warming for non-zooxanthellate species. Limnol Oceanogr 60:1356-1370

Caroselli E, Zaccanti F, Mattioli G, Falini G, Levy O, Dubinsky Z, Goffredo S (2012) Growth and demography of the solitary scleractinian coral Leptopsammia pruvoti along a sea surface temperature gradient in the Mediterranean Sea. PLoS One 7:e37848

Caroselli E, Prada F, Pasquini L, Nonnis Marzano F, Zaccanti F, Falini G, Levy O, Dubinsky Z, Goffredo S (2011) Environmental implications of skeletal micro-density and porosity variation in two scleractinian corals. Zoology 114:255-264

Carricart-Ganivet JP (2004) Sea surface temperature and the growth of the West Atlantic reef-building coral Montastraea annularis. J Exp Mar Bio Ecol 302:249-260

Carricart-Ganivet JP, Cabanillas-Teran N, Cruz-Ortega I, Blanchon P (2012) Sensitivity of calcification to thermal stress varies among genera of massive reef-building corals. PLoS One 7:e32859

Chadwick-Furman N, Goffredo S, Loya Y (2000) Growth and population dynamics of the reef coral Fungia granulosa Klunzinger, 1879 at Eilat, northern Red Sea. J Exp Mar Bio Ecol 249:199-218

Chornesky EA, Peters EC (1987) Sexual reproduction and colony growth in the scleractinian coral Porites astreoides. Biol Bull 172:161-177

Coma R, Ribes M (2003) Seasonal energetic constraints in Mediterranean benthic suspension feeders: effects at different levels of ecological organization. Oikos 101:205-215

Cooper TF, De'Ath G, Fabricius KE, Lough JM (2008) Declining coral calcification in massive Porites in two nearshore regions of the northern great barrier reef. Glob Chang Biol 14:529-538

Crossland CJ (1981) Seasonal growth of Acropora cf. formosa and Pocillopora damicornis on a high latitude reef (Houtman Abrolhos, Western Australia). Proc 4th Int Coral Reef Symp 1:663-667

D'Ortenzio F, Ribera d'Alcalà M (2009) On the trophic regimes of the Mediterranean Sea: a satellite analysis. Biogeosciences 6:139-148

Dodge R, Aller RC, Thomson J (1974) Coral growth related to the resuspension of bottom sediments. Nature 247:574-577

Edmunds P, Gates R (2002) Normalizing physiological data for scleractinian corals. Coral Reefs 21:193-197

Edmunds PJ, Gates RD, Gleason DF (2001) The biology of larvae from the reef coral Porites astreoides, and their response to temperature disturbances. Mar Biol 139:981-989

Efron B (1981) Nonparametric estimates of standard error: the jackknife, the bootstrap and other methods. Biometrika 68:589-599

Fantazzini P, Mengoli S, Pasquini L, Bortolotti V, Brizi L, Mariani M, Di Giosia M, Fermani S, Capaccioni B, Caroselli E, Prada F, Zaccanti F, Levy O, Dubinsky Z, Kaandorp JA, Konglerd P, Hammel JU, Dauphin Y, Cuif J-P, Weaver JC, Fabricius KE, Wagermaier W, Fratzl P, Falini G, Goffredo S (2015) Gains and losses of coral skeletal porosity changes with ocean acidification acclimation. Nat Commun 6:7785

Gass SE, Roberts JM (2006) The occurrence of the cold-water coral Lophelia pertusa (Scleractinia) on oil and platforms in the North Sea: colony growth, recruitment and environmental controls on distribution. Mar Pollut Bull 52:549-559

Gerrodette T (1979) Ecological studies of two temperate solitary corals. Ph.D. thesis, University of California San Diego, p 112
Gittenberger A, Reijnen BT, Hoeksema BW (2011) A molecularly based phylogeny reconstruction of mushroom corals (Scleractinia: Fungiidae) with taxonomic consequences and evolutionary implications for life history traits. Contrib Zool 80:107-132

Goffredo S, Chadwick-Furman NE (2003) Comparative demography of mushroom corals (Scleractinia, Fungiidae) at Eilat, northern Red Sea. Mar Biol 142:411-418

Goffredo S, Lasker HR (2008) An adaptive management approach to an octocoral fishery based on Beverton-Holt model. Coral Reefs 27:751-761

Goffredo S, Zaccanti F (2004) Laboratory observations of larval behavior and metamorphosis in the Mediterranean solitary coral Balanophyllia europaea (Scleractinia, Dendrophylliidae). Bull Mar Sci 74:449-458

Goffredo S, Mattioli G, Zaccanti F (2004) Growth and population dynamics model of the Mediterranean solitary coral Balanophyllia europaea (Scleractinia, Dendrophylliidae). Coral Reefs 23:433-443

Goffredo S, Airi V, Radetić J, Zaccanti F (2006) Sexual reproduction of the solitary sunset cup coral Leptopsammia pruvoti (Scleractinia, Dendrophylliidae) in the Mediterranean. 2. Quantitative aspects of the annual reproductive cycle. Mar Biol 148:923-932

Goffredo S, Caroselli E, Mattioli G, Zaccanti F (2010) Growth and population dynamic model for the non-zooxanthellate temperate solitary coral Leptopsammia pruvoti (Scleractinia, Dendrophylliidae). Mar Biol 157:2603-2612

Goffredo S, Caroselli E, Pignotti E, Mattioli G, Zaccanti F (2007) Variation in biometry and population density of solitary corals with solar radiation and sea surface temperature in the Mediterranean Sea. Mar Biol 152:351-361

Goffredo S, Caroselli E, Mattioli G, Pignotti E, Zaccanti F (2008) Relationship between growth, population structure and sea surface temperature in the temperate solitary coral Balanophyllia europaea (Scleractinia, Dendrophylliidae). Coral Reefs 27:623-632

Goffredo S, Caroselli E, Mattioli G, Pignotti E, Dubinsky Z, Zaccanti $F$ (2009) Inferred level of calcification decreases along an increasing temperature gradient in a Mediterranean endemic coral. Limnol Oceanogr 54:930-937

Goffredo S, Marchini C, Rocchi M, Airi V, Caroselli C, Falini G, Levy O, Dubinsky Z, Zaccanti F (2012a) Unusual pattern of embryogenesis of Caryophyllia inornata (Scleractinia, Caryophylliidae) in the Mediterranean Sea: maybe agamic reproduction? J Morphol 273:943-956

Goffredo S, Caroselli E, Mezzo F, Laiolo L, Vergni P, Pasquini L, Levy O, Zaccanti F, Tribollet A, Dubinsky Z, Falini G (2012b) The puzzling presence of calcite in skeletons of modern solitary corals from the Mediterranean Sea. Geochim Cosmochim Acta 85:187-199

Goffredo S, Prada F, Caroselli E, Capaccioni B, Zaccanti F, Pasquini L, Fantazzini P, Fermani S, Reggi M, Levy O, Fabricius KE, Dubinsky Z, Falini G (2014) Biomineralization control related to population density under ocean acidification. Nat Clim Chang 4:593-597

Graham EM, Baird AH, Connolly SR (2008) Survival dynamics of scleractinian coral larvae and implications for dispersal. Coral Reefs 27:529-539

Grigg RW (1984) Resource management of precious corals: a review and application to shallow water reef building corals. Mar Ecol 5:57-74

Grigg RW, Maragos JE (1974) Recolonization of hermatypic corals on submerged lava flows in Hawaii. Ecology 55:387-395

Hamel JF, Sun Z, Mecier A (2010) Influence of size and seasonal factors on the growth of deep-sea coral Flabellum alabastrum in mesocosm. Coral Reefs 29:521-525

Harriott VJ (1999) Coral growth in subtropical eastern Australia. Coral Reefs 15:281-291 
Harrison PL, Wallace CC (1990) Reproduction, dispersal and recruitment of scleractinian corals. In: Dubinsky Z (ed) Coral reefs. Elsevier, Amsterdam, pp 133-207

Howe SA, Marshall AT (2002) Temperature effects on calcification rate and skeletal deposition in the temperate coral, Plesiastrea versipora (Lamarck). J Exp Mar Bio Ecol 275:63-81

Huang D, Benzoni F, Fukami H, Knowlton N, Smith ND, Budd AF (2014) Taxonomic classification of the reef coral families Merulinidae, Montastraeidae, and Diploastraeidae (Cnidaria: Anthozoa: Scleractinia). Zool J Linn Soc 171:277-355

Hughes TP (1984) Population dynamics based on individual size rather than age: a general model with a reef coral example. Am Nat 128:778-795

Hughes TP, Jackson JBC (1985) Population dynamics and life histories of foliaceous corals. Ecol Monogr 55:141-166

Istituto Idrografico della Marina (1982) Atlante delle correnti superficiali dei mari Italiani. Istituto Idrografico della Marina, Genova, Italy

Jackson JBC (1986) Modes of dispersal of colonial benthic invertebrates: consequences for species' distributions and genetic structure of local populations. Bull Mar Sci 39:588-606

Johnson KG (1992) Population dynamics of a free-living coral: recruitment, growth and survivorship of Manicina areolata (Linnaeus) on the Caribbean coast of Panama. J Exp Mar Bio Ecol 225:253-267

Jokiel PL, Guinther EB (1978) Effects of temperature on reproduction in the hermatypic coral Pocillopora damicornis. Bull Mar Sci 28:786-789

Kain JM (1989) The seasons in the subtidal. Br Phycol J 24:203-215

Kitahara MV, Cairns SD, Miller DJ (2010) Monophyletic origin of Caryophyllia (Scleractinia, Caryophylliidae), with descriptions of six new species. System Biodivers 8:91-118

Knittweis L, Jompa J, Richter C, Wolff M (2009) Population dynamics of the mushroom coral Heliofungia actiniformis in the Spermonde Archipelago, South Sulawesi, Indonesia. Coral Reefs 28:793-804

Kozłowski J, Wiegert RG (1986) Optimal allocation of energy to growth and reproduction. Theor Popul Biol 29:16-37

Krief S, Hendy EJ, Fine M, Yam R, Meibom A, Foster GL, Shemesh A (2010) Physiological and isotopic responses of scleractinian corals to ocean acidification. Geochim Cosmochim Acta 74:4988-5001

Kružić P, Sršen P, Benković L (2012) The impact of seawater temperature on coral growth parameters of the colonial coral Cladocora caespitosa (Anthozoa, Scleractinia) in the eastern Adriatic Sea. Facies 58:477-491

Lasker HR (1990) Clonal propagation and population dynamics of a gorgonian coral. Ecology 71:1578-1589

Leuzinger S, Willis BL, Anthony KR (2012) Energy allocation in a reef coral under varying resource availability. Mar Biol 159:177-186

Lough JM, Barnes DJ (2000) Environmental controls on growth of the massive coral Porites. J Exp Mar Bio Ecol 245:225-243

Marchini C, Airi V, Fontana R, Tortorelli G, Rocchi M, Falini G, Levy O, Dubinsky Z, Goffredo S (2015) Annual reproductive cycle and unusual embryogenesis of a temperate coral in the Mediterranean Sea. PLoS One 10:e141162

Muscatine L, Falkowski PG, Dubinsky Z, Cook PA, McCloskey LR (1989) The effect of external nutrient resources on the population dynamics of zooxanthellae in a reef coral. Proc R Soc Lond B Biol Sci 236:311-324

Orejas C, Ferrier-Pagès C, Reynaud S, Gori A, Beraud E, Tsounis G, Gili JM (2011) Long-term growth rates of four Mediterranean cold-water coral species maintained in aquaria. Mar Ecol Prog Ser 429:57-65
Pauly D (1984) Fish population dynamics in tropical waters: a manual for use with programmable calculators. International Center for Living and Aquatic Resources Management, Manila, The Philippines

Peirano A, Morri C, Bianchi CN (1999) Skeleton growth and density pattern of the temperate, zooxanthellate scleractinian Cladocora caespitosa from the Ligurian Sea (NW Mediterranean). Mar Ecol Prog Ser 185:195-201

Peirano A, Damasso V, Montefalcone M, Morri C, Bianchi CN (2005) Effects of climate, invasive species and anthropogenic impacts on the growth of the seagrass Posidonia oceanica (L.) Delile in Liguria (NW Mediterranean Sea). Mar Pollut Bull 50:817-822

Purser A, Larsson AI, Thomsen L, Van Oevelen D (2010) The influence of flow velocity and food concentration on Lophelia pertusa (Scleractinia) zooplankton capture rates. J Exp Mar Bio Ecol 395:55-62

Reynaud S, Leclercq N, Romaine-Lioud S, Ferrier-Pagès C, Jaubert J, Gattuso JP (2003) Interacting effects of $\mathrm{CO}_{2}$ partial pressure and temperature on photosynthesis and calcification in a scleractinian coral. Glob Chang Biol 9:1660-1668

Roberts JM, Long D, Wilson JB, Mortensen PB, Gage JD (2003) The cold-water coral Lophelia pertusa (Scleractinia) and enigmatic seabed mounds along the north-east Atlantic margin: are they related? Mar Pollut Bull 46:7-20

Rodolfo-Metalpa R, Richard C, Allemand D, Bianchi CN, Morri C, Ferrier-Pagès C (2006) Response of zooxanthellae in symbiosis with Mediterranean corals Cladocora caespitosa and Oculina patagonica to elevated temperatures. Mar Biol 150:45-55

Rodolfo-Metalpa R, Peirano A, Houlbrèque F, Abbate M, FerrierPagès C (2008) Effect of temperature, light and heterotrophy on the growth rate and budding of the temperate coral Cladocora caespitosa. Coral Reefs 21:17-25

Sakai K (1998) Effect of colony size, polyp size, and budding mode of egg production in a colonial coral. Biol Bull 195:319-325

Sebens KP (1987) The ecology of indeterminate growth in animals. Annu Rev Ecol Syst 18:371-407

Sparre P, Venema SC (1998) Introduction to tropical fish stock assessment. Part 1: Manual. FAO Fisheries Technical Paper No. 306, Rev. 2. FAO, Rome

Sparre P, Ursin E, Venema SC (1989) Introduction to tropical fish stock assessment. FAO Fisheries Technical Paper. FAO, Rome

Squires DF (1959) Deep-sea corals collected by the Lamont geological observatory. 1. Atlantic corals. Am Mus Novit 165:1-42

Teixidó N, Garrabou J, Harmelin JG (2011) Low dynamics, high longevity and persistence of sessile structural species dwelling on Mediterranean coralligenous outcrops. PLoS One 6:e23744

Vertino A, Savini A, Rosso A, Di Geronimo I, Mastrototaro F, Sanfilippo R, Etiope G (2010) Benthic habitat characterization and distribution from two representative sites of the deep-water SML Coral Province (Mediterranean). Deep Sea Res Part 2 Top Stud Oceanogr 57:380-396

von Bertalanffy L (1938) A quantitative theory of organic growth (inquiries on growth laws II). Hum Biol 10:181-213

Vongsavat V, Winotai P, Meejoo S (2006) Phase transitions of natural corals monitored by ESR spectroscopy. Nucl Instrum Methods Phys Res B 243:167-173

Yamashiro H, Nishihira M (1998) Experimental study of growth and asexual reproduction in Diaseris distorta (Michelin, 1843), a free-living fungiid coral. J Exp Mar Bio Ecol 225:253-267

Zibrowius H (1980) Les scléractiniaires de la Méditeranée et de l'Atlantique nord-oriental. Mem Inst Oceanogr (Monaco) $11: 1-284$ 